\title{
Toilet training: what can the cookstove sector learn from improved sanitation promotion?
}

\author{
Temilade Sesan $^{\mathrm{a} *}$, Sarah Jewitt ${ }^{\mathrm{b}}$, Mike Clifford $^{\mathrm{c}}$, Charlotte Ray $^{\mathrm{c}}$ \\ ${ }^{a}$ Centre for Petroleum, Energy Economics and Law, 7 Parry Road, University of \\ Ibadan, Oyo State, Nigeria. \\ ${ }^{b}$ School of Geography, University of Nottingham NG7 2RD, UK \\ ${ }^{c}$ Faculty of Engineering, University of Nottingham NG7 2RD, UK \\ *Corresponding author.
}

Email address: temi@gbengasesan.com

Temilade Sesan is a sociologist of international development, with qualitative research experience in the areas of energy, gender, and health. Geographically, her research has focused on West Africa, particularly Nigeria and Ghana, and East Africa. She has published extensively on the interactions between the market-based trajectories envisaged for improved cookstove programs and the socio-economic realities of local target groups.

Sarah Jewitt is an Associate Professor in the School of Geography at the University of Nottingham. She has research interests in rural development, sanitation, decentralized rural energy, gender, indigenous knowledge and forest management. She is currently involved in research projects focusing on sanitation uptake and gendered priorities in India and strategies for improving nitrogen use efficiency in Brazil.

Mike Clifford is an Associate Professor in the Faculty of Engineering at the University of Nottingham. He is also a volunteer with the UK Relief and Development Charity, Tearfund, and works on appropriate technology projects across sub-Saharan Africa, particularly related to cooking technologies. 
Charlotte Ray has expertise in human geography, international development, livelihoods, displacement, food security, qualitative methodology and household energy systems in the global South. Her PhD thesis investigated the integration and livelihood strategies of "selfsettled" refugee communities in The Gambia, West Africa, understanding the cross-border social, cultural and historical ties that influence the availability of and access to resources for both hosts and refugees. Presently her research interests lie in the energy sector investigating how households interact with, adopt, and sustainably use cooking technologies in East and Southern Africa. 


\title{
Toilet training: what can the cookstove sector learn from improved sanitation promotion?
}

\author{
Within the domain of public health, commonalities exist between the sanitation \\ and cookstove sectors. Despite these commonalities and the grounds established \\ for cross-learning between both sectors, however, there has not been much \\ evidence of knowledge exchange across them to date. Our paper frames this as a \\ missed opportunity for the cookstove sector, given the capacity for user-centred \\ innovation and multi-scale approaches demonstrated in the sanitation sector. The \\ paper highlights points of convergence and divergence in the approaches used in \\ both sectors, with particular focus on behaviour change approaches that go \\ beyond the level of the individual. The analysis highlights the importance of the \\ enabling environment, community-focused approaches and locally-specific \\ contextual factors in promoting behavioural change in the sanitation sector. Our \\ paper makes a case for the application of such approaches to cookstove \\ interventions, especially in light of their ability to drive sustained change by \\ matching demand-side motivations with supply-side opportunities.
}

Keywords: behaviour change communication; clean cooking; community-wide participatory approaches; improved sanitation; multi-level approaches

\section{Introduction}

Recent statistics indicate that around 892 million people worldwide practice open defecation (OD) while 2.3 billion use "unimproved" sanitation facilities such as flush/pour-flush toilets unconnected to piped sewers or septic tanks, open pits, bucket toilets, hanging latrines and open fields (WHO/UNICEF 2017). Similarly, around 2.9 billion people globally rely on "traditional" biomass fuels (primarily wood and charcoal, but also animal dung, crop residue and other readily available organic matter) for cooking and heating (IEA and World Bank 2015). These widespread sanitation and cooking practices are associated with environmental and health risks which contribute significantly to the global burden of disease: Lim et al.'s analysis of data from the 2010 Global Burden of Disease study showed that biomass-induced household air pollution 
(HAP) and poor sanitation contributed 4.3 percent and 0.9 percent of global disability adjusted life years (DALYs) respectively in that year (Lim et al. 2012). The study also placed HAP as the third-most important risk factor globally (and the second-most important for women); the leading cause of death in south Asia; and the second-most important risk factor in western, eastern and central sub-Saharan Africa (ibid.). ${ }^{1}$ Although water and sanitation access declined from 15th to 34th position on the global risk factor table between 1990 and 2010, it continues to rank between the seventh and ninth most important risk factor in western, eastern and central sub-Saharan Africa and remains the nineteenth most important risk factor in south Asia (ibid.).

Major diseases linked to HAP and a lack of access to modern cooking fuels (most commonly gas and electricity) and stoves include cancers, childhood pneumonia, heart disease, chronic respiratory diseases, cataracts, and burns (GACC n.d., IEA and World Bank 2015). Poor sanitation access, on the other hand, is associated with exposure to soil-transmitted helminth (STH) infections, trachoma, schistosomiasis and diarrhoeal diseases which are linked to $19 \%$ of deaths among children under five in low-income areas along with severe childhood stunting (Freeman et al., 2017). These effects make unimproved water/sanitation and HAP leading causes of mortality worldwide: The number of deaths collectively attributed to poor water and sanitation access in 2010 was 360,232 , while HAP, responsible for 3,478,773 mortality cases in the same year, was nearly ten times as deadly (Lim et al. 2012).

The parallels between the incidence and health impacts of HAP and poor sanitation access, as well as between the "improved" technologies (or "hardware")

\footnotetext{
${ }^{1}$ In addition, several systematic reviews of the evidence on HAP reduction (for example, Bruce et al. 2013, Amegah et al. 2014, Jary et al. 2016 and Quansah et al. 2017) have established linkages between solid biomass use and poor health outcomes, especially among vulnerable groups like children and pregnant women.
} 
promoted by a range of development actors to mitigate those impacts, are striking. Improved cookstoves (ICS) have historically been targeted at decreasing biomass consumption and/or reducing smoke emissions, depending on the particular threat that was considered top priority by development actors at a given point in time (Ezzati and Kammen 2002, Foell et al. 2011). Over the past four decades, an assortment of ICS has been introduced through various approaches, with contemporary cookstoves boasting terminology such as "clean," "modern" or "advanced" which reflect ever-increasing levels of technological sophistication (Bailis et al. 2009, Venkataraman et al. 2010). On the other hand, according to tracking criteria set out under Sustainable Development Goal 6.2 a sanitation system is considered to meet a "basic" level of service if it is characterised by an "improved" sanitation facility that "hygienically separates human excreta from human contact" (WHO/UNICEF 2016). Technologies that meet this criterion include flush/pour-flush toilets that discharge to piped sewers or septic tanks, pit latrines with slabs, ventilated improved pit latrines and composting toilets (ibid.). A number of other significant similarities are evident. The uptake of improved sanitation and cooking technologies is often resisted for cultural and socio-economic reasons; especially where existing practices - OD in the case of sanitation and fuelwood gathering for cooking on traditional stoves - are free of economic cost and/or actively preferred by end-users (Coffey et al. 2014, Hiemstra-van der Horst and Hovorka 2009). As this paper will show, the public health implications of such resistance are significant. The health benefits of sanitation, for example, are only likely to be fully realised for individuals if everyone in a community uses improved toilets exclusively and on a sustained basis (Clasen et al 2014; Patil et al 2014). Likewise, the use of clean stoves / fuels or ICS by a subset of households in a community will not protect them from exposure to pollution from unimproved biomass stoves used by other households or 
from outdoor sources (such as bush burning) within the community (Clifford 2014, Johnson and Chiang 2015). The recognition of the public dimension to both phenomena and the efficacy of improved technologies aimed at addressing them has a longer history in the sanitation sector than in the cookstove sector (see GACC, n.d.) - an observation which, as we will see, offers opportunities for learning in the latter.

Indeed, the degree of similarity between the sanitation and cookstove sectors the significant health burdens imposed by the status quo, the predication of change on the near-universal uptake of technologies considered to be improved by external actors (but not necessarily by local populations), and the preponderance of non-technical barriers to achieving large-scale change (Gutierrez 2007) - would appear to imply the inevitability of learning across both sectors. However, while there is growing acknowledgement of the general applicability of behaviour change models - long established in the sanitation field - to the cookstove sector (see, for example, Rosenthal et al. 2017), there is little evidence of focused attempts to transfer lessons from the application of specific sanitation models that have proved instructive over time to the goal of HAP reduction. This is potentially a missed opportunity, especially given that much greater balance has been achieved between supply-side initiatives and demand-led interventions in the sanitation sector over time, fostering examples of both success and failure that can inform cookstove practice.

Our paper begins by exploring the evolution of global efforts to promote and track improved sanitation and cooking systems respectively, highlighting the gradual shift in each sector from frequently subsidy-led top-down approaches focused on the dissemination of technological hardware towards greater recognition of the need for more culturally sensitive implementation and more inclusive agendas. Crucially, we argue that, since the environmental and health benefits associated with improved 
cooking technologies cannot be fully realised until entire populations exclusively adopt and utilise them, there is an urgent need to better understand user preferences and constraints as well as the socio-economic and cultural factors underlying these. This is critical for stimulating user demand from the bottom up, to complement the supply-side approaches typically emphasised by high-profile cookstove initiatives. The paper's originality and significance lie in its emphasis on how lessons learned from more userfocused and multi-scale behavioural change approaches to implementing technological solutions in the sanitation sector (Dreibelbis et al. 2013) might transfer to the cookstove sector. The findings have particular relevance for researchers and practitioners working on water, sanitation, improved cookstoves, public health and behaviour change interventions.

\section{The traditional focus on hardware in sanitation and the shift to demand-led approaches}

Global efforts to increase access to improved sanitation stretch back over 40 years. For most of this period, affordability has been recognized as a key barrier to the uptake of improved sanitation facilities amongst lower income groups (WHO/UNICEF 2015). In response, target- and subsidy-led "technology-oriented" approaches focusing on latrine construction and the provision of sanitary hardware have been widely employed (O'Reilly and Louis 2014). Critiques of such approaches include their ineffectiveness in promoting increased latrine use, a tendency to suffer from elite capture and poor sustainability (Kar and Pasteur 2005, Jenkins and Sugden 2006, Bongartz and Chambers 2009, O'Reilly 2010, O'Reilly and Louis 2014). Moreover, the presence of a toilet is often insufficient to motivate sustained usage (Heierli and Frias 2007, Devine 2009) with "backsliding" occurring as users revert to OD and toilets fall into disuse (Sanan 
and Moulik 2007). Drawing on analogies from the cookstove sector (Masera et al, 2000), meanwhile, the simultaneous use or "stacking" of various sanitation methods by different household members - often reflecting cultural/gendered preferences for OD, seasonal variations in access/functionality or excessive demand for household latrines can undermine potential health gains from increased latrine coverage (Clasen et al. 2014, Jewitt et al. 2018, Patil et al. 2014).

Though there remains an overwhelming focus in the field on distributing hardware - especially in poor rural areas where affordability is deemed to be especially low (Murray and Ray 2010, Sanan and Moulik 2007) - increased attention has been paid to software-oriented approaches that seek to address failures associated with subsidy-led approaches by understanding and targeting the determinants of sanitation behaviour in different local contexts (Dreibelbis et al. 2013, Wells and Sijbesma 2012). A key lesson taken on board by such approaches is that supply follows user demand - not the other way around as is implicitly assumed in hardware- and subsidy-oriented approaches. Stimulating a shift from OD is therefore considered an important first step in creating demand for improved facilities (Heierli and Frias 2007, Jenkins and Curtis 2005, Kar 2003). Furthermore, experience in the sector has indicated that demand-led and supplyled initiatives can be complementary in achieving adoption and sustained use of improved technologies (Bardosh 2015).

Given recognition of the limitations of increased access to sanitation facilities or exposure to information on the health benefits of latrine use (typically through "education" or "awareness" campaigns) in motivating sustained use, the science of behaviour change has taken on increasing importance in the sector (Barnes et al. 2015, Aboud and Singla 2012, Parkes et al. 2003). Against this background, a potpourri of 
behaviour change approaches has been applied to the challenge of understanding and driving sanitation uptake (Driebelbis et al. 2013, UNICEF 2013). Interventions linked to these approaches fall into two main categories: communication approaches, which tend to target individuals; and participatory approaches, which usually have a more community-wide focus.

\section{Communication approaches}

The most widespread communication approach is sanitation marketing (Evans et al. 2014, Lewis et al. 2015, MacInnis et al. 1991), a key emphasis of which is on “selling" improved sanitation practices (Aboud and Singla 2012, Briscoe and Aboud 2012) and stimulating demand to the point of facilitating autonomous market exchange between hardware suppliers and prospective buyers (Barrington et al. 2016). A key component is behaviour change communication based on information campaigns and product advertisement (Jenkins and Scott 2007). Such approaches are often influenced by models that seek to theorise and explain behaviour change related to water, sanitation and hygiene (WASH) (Dreibelbis et al. 2013). For example, the World Bank's SaniFOAM framework identifies three main categories of behavioural determinants linked to motivation (the desire/willingness of a household to acquire an improved sanitation facility), ability (the capacity of a household to pay for a sanitation facility) and opportunity (the chance to fulfil that desire through market exchange). The RANAS model, meanwhile, identifies five key behavioural factors (risk, attitudinal, normative, ability and self-regulation) which can be targeted with specific interventions (information, persuasive and infrastructural) (Mosler 2012).

Though much of the sanitation literature describes behaviour change communication as being demand-led, Devine (2009) highlights key limitations 
associated with the emphasis of many such approaches on ability and opportunity rather than motivation. Tapping into motivational factors means gaining insight into users' value systems, attitudes, emotional associations, psychological processes, socioeconomic influences, priorities, and aspirations (ibid.) - all of which require a level of user engagement that the design of sanitation marketing interventions often does not support.

Other key limitations pointed out by Dreibelbis et al. (2013) include the failure of behaviour change frameworks to consider broader aspects of WASH behaviour (such as socio-economic status, resource availability, gender, age) and their prioritisation of individual-level behaviour over how this operates within "a multi-level causal framework". They also highlight the failure of most behaviour change models to consider the habitual use of WASH technologies in addition to their initial adoption. ${ }^{2}$

To address these shortcomings, Dreibelbis et al. outline the IBM-WASH model which considers how contextual (wider environmental factors), psychosocial (psychological, social, or behavioural factors) and technological (attributes and ease of use of the technology being adopted) considerations influence WASH-related behaviour. The model considers these influences at multiple levels ranging from the individual, through to the household, community and structural/societal levels. A fifth level considers factors affecting habitual use, although the model also acknowledges the importance of understanding the dynamic nature of WASH behaviour as people use (or "stack" - Jewitt et al. 2018) different technologies depending on the season or their

\footnotetext{
${ }^{2}$ Key exceptions include SaniFOAM's consideration of contextual factors such as affordability and household-based decision making, Figueroa and Kincaid's (2010) multi-level consideration of individual contextual factors (such as household income and decision-making) and community-level influences (such as leadership and cohesion) and the focus on habitual use of WASH technologies as well as adoption by the Stages of Change Model used by Jenkins and Scott (2007) in Ghana and Wood et al. (2012) in Malawi.
} 
location. As will be apparent from the discussion below, the multi-level approach presented by this model offers important lessons for both sanitation and cookstove practice.

\section{Community-focused participatory approaches}

A different set of lessons is offered by community-focused approaches in the sanitation sector that employ reflexive methods to understand the reasons behind poor health practices in households and communities, bring those reasons to the consciousness of targeted users, and help them to independently arrive at a new rationale for engaging in improved practices. Community-focused participatory approaches have been particularly effective in exploring the deep-seated and multi-level drivers of poor sanitation practices in households and communities. The most prominent of these approaches are Community Health Clubs (CHCs), Participatory Hygiene and Sanitation Transformation (PHAST), and Community-led Total Sanitation (CLTS) (Barrington et al. 2016). All three approaches contain elements of Friere's (1996) “conscientization” theory, which holds that individuals can, through a process of facilitation, be sensitized to their needs and capabilities and be empowered to become active agents of the change they desire. A key lesson learned from CHCs and PHAST is that collective change can be hinged on individual exposure to knowledge and peer-to-peer information exchange (at group level) rather than a transactional impartation of information from donor to beneficiary (Waterkeyn and Cairncross 2005). Community-led Total Sanitation (CLTS), meanwhile, predicates collective change on the ability to "trigger" awareness and resolve at the level of the community rather than that of the individual and illustrates how the community-wide shift from OD needed for effective disease containment can be achieved (Sanan and Moulik 2007). 
Strikingly, CLTS discourages the pattern of subsidy reliance that is common with hardware-focused programmes, reasoning that people will pay to build their own toilets if the subject is important enough to them (Kar and Pasteur 2005). Indeed, a key lesson to be learned from CLTS is how the triggering process gets households and communities to reassess their priorities in such a way that sanitation becomes a key concern. As with mainstream behaviour change interventions, therefore, supply is expected to follow demand, rather than the other way around. In the most successful CLTS cases, awakened household appetites for sanitation have indeed spawned vibrant and far-reaching local markets with competitively priced materials even in stereotypically poor rural locations, with little external prompting (Kar 2003, Heierli and Frias 2007).

Nonetheless, there has been concern over some of the means used to establish new sanitation norms under CLTS, especially those involving shaming or sanctions that disproportionately disadvantage poorer households within a community (Engel and Susilo 2014, McMichael and Robinson 2016). Further, the rapid spread of latrine construction typically triggered by CLTS comes with a risk of failure: many of the selfhelp latrines built are low-cost, basic structures with short life spans, introducing the possibility that poor households that find their latrines unusable after a while will "backslide" and return to OD (Bardosh 2015, Cavill et al. 2015). ${ }^{3}$ These weaknesses notwithstanding, however, the ethos of substantive community participation and monitoring propagated by the approach - on a level that exemplifies the ideal that

\footnotetext{
${ }^{3}$ A recent systematic review by Freeman et al. (2017) found no studies comparing OD with unimproved sanitation. As a result, the health-related implications of using unimproved rather than improved latrines or of "backsliding" from unimproved latrines to OD are unclear.
} 
Drijver (1991) refers to as "functional reach" in participatory development projects offers important learning opportunities.

\section{Combining sanitation approaches in practice}

The sanitation sector has examples of multi-level initiatives seeking to achieve functional reach and cost-effectiveness by combining key elements of behaviour change communication and community-wide participatory approaches. These include India's Total Sanitation Campaign (TSC) and Nirmal Bharat Abhiyan (NBA) which were designed as demand-driven multi-scale programmes with elements of behaviour change communication and CLTS plus subsidies to enable "below poverty line" households to construct latrines (Casen et al. 2014, Patil et al. 2014, MDWS 2017, Pattanayak et al 2009, Sanan and Moulik 2007). To counteract anticipated failures associated with subsidy-led approaches, CLTS elements were used to "trigger" communities into responding to the shame of OD and understanding the health risks it presented for everyone, while psychosocial influences (including social sanctions, shaming and fines) were used to help prevent "backsliding" (Pattanayak et al 2009). At the societal level, sanitation marts and additional capacity building, training, monitoring and financial support were provided by public health engineers, district officials and a range of NGO partners. An approach that proved successful in helping to overcome individual-level inertia and promoting a desire to live in sanitary settlements was the award of monetary prizes for villages, blocks and districts that achieved ODF status (ibid., Patil et al. 2014).

Important lessons about the implementation of large-scale behaviour change initiatives can also be learned from India's Swachh Bharat (Clean India) Mission (SBM) which was launched in 2014 as part of a drive to address sanitation stacking and end OD by 
Mahatma Gandhi's $150^{\text {th }}$ birthday anniversary on 2nd October 2019. Through an extension of the CLTS/communication/subsidy approaches used in the TSC/NBA, coupled with elements of strong political will, financial incentives, multi-scale peer- and institutional support, capacity building, implementation and monitoring mechanisms (Alexander et al. 2016, MDWS 2017), the SBM deploys many of the IBM-WASH model's multi-level behaviour change approaches (Driebelbis et al. 2013).

As of June 2018, the SBM was reporting 85.38 percent sanitation coverage along with 17 ODF states, 392 ODF Districts, 385,149 ODF villages and the construction of 7,458,1298 improved household toilets since October 2014 (MDWS 2018). Although the accuracy of these data and the quality of monitoring have been critiqued (The Economic Times, 2017), the level of behavioural change achieved by the SBM is nevertheless unprecedented. Its multi-level emphasis with sustained financial investment and political buy-in, coupled with efforts to open communities up to problems that need to be tackled without relying on outsider "experts" promoting a predetermined set of "solutions" is quite novel in the development sector. The rest of the paper examines parallel developments in the cookstove sector and the lessons that the sector can learn from the sanitation approaches analysed above.

\section{The relatively recent rise of behaviour change approaches in the cookstove sector}

In Hanna et al.'s (2012) influential report on the findings of a randomised controlled trial (RCT) conducted with 2,651 households in India, the authors point out that the majority of the low-cost improved cookstoves used in real-life conditions do very little to reduce users' exposure to smoke and nothing whatsoever to mitigate the health impacts of that exposure. This outcome, the authors claim, is primarily due to changes 
(or the lack thereof) in the behaviour of cooks using ICS over an extended period of time - four years, in the case of the RCT. Echoing lessons from the sanitation sector in relation to the limited health gains associated with insufficient sanitation coverage or sustained use (Casen et al. 2014, Patil et al. 2014, Freeman et al. 2017), the cooks followed by the study used their ICS with declining intensity over time, stopped using them exclusively, and did not carry out routine maintenance and repairs on the ICS as instructed. Partly as a result of these behavioural factors, but also due to the toll taken by time on the ICS themselves, the technical performance of the stoves dropped over the study period, rendering them ineffective at reducing smoke emissions over the long term. ${ }^{4}$ A major contention of the Hanna et al. report is that, if contingent behavioural factors preclude realisation of the health and environmental benefits claimed for lowcost ICS like the one in the study, why continue to expend so much financial and political capital trying to distribute them at scale? One possible rationale for this is offered by the sanitation sector, where the widespread shifts to basic latrines from OD facilitated by CLTS approaches, while not sufficient to achieve the targeted health gains, often acted as a catalyst for moving communities one step away from hazardous traditional practices.

The response to this challenge in the cookstove sector, meanwhile, has been an abrupt leap in international policy discourse from promoting low-tech but culturally appropriate ICS to championing the idea of "clean" cookstoves (mostly gas-fuelled

\footnotetext{
${ }^{4}$ Notably, a more recent RCT conducted with over 8,000 households in Malawi (Mortimer et al. 2017) reported similar findings in relation to the decline in consistency of use of newly introduced ICS over the medium term ( 2 years) and the resulting lack of impact on users' health over the period. The results of another ICS trial conducted in Nepal were deemed so unfavourable that the authors concluded that the desired emission reductions can only be achieved with modern stoves and fuels like LPG or ethanol (Tielsch et al. 2016); however, the conclusions of an RCT which tested the effects of replacing kerosene stoves with bioethanol stoves among pregnant women in Nigeria (Olopade et al. 2017) were not so definitive.
} 
stoves but also stoves fuelled by processed biomass), on the basis that these are the only technologies that are truly capable of delivering "health-protective" levels of smoke reduction to users (Lewis et al. 2015) - seemingly reflecting the hardware-focused orthodoxy embraced by traditional sanitation projects. This response however misses the larger point raised by a wide range of observers, which is that, even where improved or clean cookstoves have been proven to be capable of delivering health benefits to users, there is evidence that knowledge of these benefits alone is not enough to spur adoption and use of those technologies by biomass-reliant households (Beltramo et al. 2014, Clark et al. 2015, Thurber et al. 2014, USAID 2014). Echoing lessons from more recent efforts to promote improved sanitation facilities, poor households may value and prioritise certain attributes of ICS and clean cookstoves (and may purchase them for those attributes), but these do not usually include the health benefits claimed for those technologies (Barstow et al. 2014, Bhojvaid et al. 2014, Martin et al. 2013). As such, the long-standing assumption in the field that increasing public awareness of the health benefits of using clean cookstoves would lead to greater uptake has come into question.

Even where some degree of uptake has been realised for clean cookstoves, many of the issues with low-cost ICS raised by Hanna et al. (2012) have still been found to apply. Mainstream cookstove promoters now acknowledge that it is not sufficient to only drive adoption, and increasing attention is now being paid to identifying the factors that influence "correct," sustained, and potentially even exclusive use of those stoves, with a view to achieving the levels of HAP reduction envisaged for users (Clark et al. 2015, Martin et al. 2013). The push for the exclusive use of clean cookstoves is occurring in spite of the availability of a large body of evidence which shows that a confluence of social, cultural and economic factors makes stove/fuel stacking - a practice by which many households in developing-country contexts combine different 
stoves and fuels to meet a range of cooking needs (and which, as indicated above, is mirrored in sanitation) - the norm in target communities (Ruiz-Mercado and Masera 2015, Piedrahita et al. 2016). The optimism among advocates that these established patterns can nonetheless be altered by external intervention is the premise of the recent shift towards a behaviour change paradigm in the cookstove sector (Harrell et al. 2013).

As indicated earlier, a defining feature of this new paradigm is a partiality towards advanced stove technologies and "modern" (especially fossil) fuels. However, advocates of behaviour change approaches in the field recognise that it is not enough to simply laud the superior technical features of the so-called "higher-tier" stoves and fuels they typically promote (Bruce et al. 2015); it is important to also anticipate and harness the ways in which users are likely to interact with those technologies within specific local contexts (in essence, combining the contextual and technological dimensions of the IBM-WASH model), as it is these complex micro-level interactions that will determine the efficacy or otherwise of cookstove interventions (Goodwin et al. 2015, Rosenthal and Borrazzo 2015).

In general, the methods and strategies grouped under the umbrella of behaviour change techniques in the cookstove sector are a combination of long-established approaches in the field and relatively new ones that are more consistent with the innovative label that is liberally applied across interventions. Strategies like subsidy provision, participatory cookstove design, cooking demonstrations, peer-to-peer networking and partnership, enhancing the affordability of stoves by using locally available materials for production, and leveraging the influence of local leaders to promote particular cookstoves, are all approaches that have been used extensively by implementing organisations in the past, especially those who have historically championed appropriate technology and participatory development objectives (Khennas 
2003). On the other hand, strategies like the development of coordinated media campaigns, the provision of microfinance, the extension of promotional offers to prospective buyers, and the delivery of after-sales services to customers are more novel. As has been done for the sanitation sector, it is possible to classify each of these strategies as either a supply-focused communication approach (for example, media campaigns and promotional offers) or a demand-focused community approach (for example, participatory cookstove design and peer-to-peer networking). The emerging lesson here, as demonstrated by the India sanitation campaigns analysed above, is that these strategies can be systematically combined in practice so that the strengths of one set of approaches are able to compensate for the apparent limitations of the other. The potential outcome, as the ongoing SBM in India illustrates, is wider uptake and sustained use of higher-quality cookstoves than has been achieved with traditional onesided approaches.

Though behaviour change interventions attempt to set themselves apart from traditional awareness-raising approaches by digging deeper into the human factors influencing cookstove adoption and use Barnes et al. (2015), they do not address the fundamental issue of why poor households would want to use an ICS or clean cookstove in the first instance. ${ }^{5}$ Further, they do not engage with the question of why households would want to prioritise living in a smoke-free community - a shortcoming that can be addressed by adopting lessons apparent from the success of the CLTS approach in promoting the overarching goal of ODF communities (rather than focusing

\footnotetext{
${ }^{5}$ There is, however, evidence of a certain degree of responsiveness of behaviour change interventions: some interventions, for example, emphasise deep community engagement through "grassroots marketing efforts" (Harrell et al. 2013), in the process leveraging the influence and support of formal and informal authorities and institutions for product promotion at the local level (Barstow et al. 2014, SEI 2016). The outcomes of experiments conducted in Uganda (Beltramo et al. 2014) and Bangladesh (Rosenbaum et al. 2015) show that such promotional strategies encourage cookstove uptake, especially among poor households where cost is a major consideration.
} 
on any one improved technology as the solution for households). Instead, the focus of conventional behaviour change approaches is on the process of cookstove adoption and use, assuming a priori that this is where the barriers to uptake lie, rather than at the level of what individuals and communities prioritise for a range of context-specific reasons (see Sesan 2012, Troncoso et al. 2007). In essence, behaviour change proponents approach cookstove interventions with an end in mind, which is to persuade target households to adopt advanced or clean cookstoves that had very high barriers to uptake to begin with (Bhojvaid et al. 2014). Linked to this is the heavy focus of such interventions on product promotion and marketing, a strategy which has been justified by the explanation that cookstoves, unlike aspirational products such as mobile phones, come up against considerable levels of user inertia that need to be proactively countered (Shell Foundation 2013).

As the paper goes on to discuss, this aspect of countering inertia is where the cookstove sector could draw the most immediately relevant lessons from the CLTS approach, with the emphasis of the latter on getting communities to take a first step away from unhealthy traditional practices. Learning from the large-scale behaviour change approaches used to promote sanitation uptake in India, the use of CLTS principles with multi-level approaches has the potential to enable better integration of individual with household, community and societal components, so that change is simultaneously achieved at multiple scales (Dickin et al. 2017, Dreibelbis et al. 2013). Such hybrid approaches would be especially valuable in this phase of cookstove development where, despite increasing recognition that interventions are needed that can deliver positive health outcomes at "population level” (USAID 2014), contemporary behaviour change approaches still tend to be overwhelmingly directed towards influencing decisions at the individual and household levels. The concluding 
section elaborates on specific aspects of sanitation-related behaviour change interventions that appear to be of particular relevance to the ICS sector.

\section{Conclusion: Emerging lessons for the cookstove sector}

This review has traced the evolution of cookstove programmes over the last decade. Echoing findings from the sanitation sector (Clasen et al. 2014, Patil et al. 2014), several randomised controlled trials have found low-cost ICS to be ineffective at improving health outcomes over the long term. The overwhelming response of mainstream cookstove actors to these findings has been to advocate for the introduction of more technologically advanced (and, by extension, more expensive) cookstoves that are, in theory, capable of delivering the degree of emission reductions necessary for realising appreciable health gains. It is however becoming increasingly clear to proponents of this strategy that awareness of cookstoves' technical capabilities, and of the associated gains, is in itself not sufficient to drive uptake among target populations. This realisation has prompted mainstream embrace in the cookstove field of the behaviour change paradigm that has held sway in the sanitation sector (as well as other health-related sectors) for a much longer period (USAID and URC 2015).

However, the evidence from the cookstove literature indicates that the majority of behaviour change interventions in the field rely on strategies that only partially acknowledge the complexities involved in engaging with the multidimensional realities of local contexts (Goodwin et al. 2015). Critically, these interventions focus on building market channels and sales opportunities for particular cookstoves while neglecting the more fundamental question of what might motivate individuals and communities to prioritise such a goal as smoke reduction in the first place. This question has long been pondered in the sanitation field, giving rise to models such as the SaniFOAM 
framework (Devine 2009), the IBM-WASH model (Dreibelbis et al. 2013) and the CLTS approach (Kar 2003) that prioritise the kind of in-depth psychosocial engagement that is required to elicit the motivations underpinning people's responses to particular interventions in a given context. Further, these sanitation approaches link individuals' motivation to an appreciation of how their actions promote the common good contributing to change on a level that is necessary for achieving the goals of habitual use and improved health among target populations. Our paper argues that, by consciously drawing lessons from relevant aspects of these sanitation approaches, the cookstove sector can emerge with multi-level yet community-focused behaviour change methodologies to better respond to the challenge of reducing HAP in biomass-reliant regions.

India's Total Sanitation Campaign/Nirmal Bharat Abhiyan (TSC/NBA) and Swachh Bharat Mission (SBM) demonstrate how this can be done. In these programmes, CLTS approaches were combined with subsidies, communication activities and a range of multi-level peer-support networks to significantly increase sanitation coverage and - importantly in the context of overcoming the inertia inhibiting the adoption of new practices - speed up the achievement of ODF status for hundreds of communities. In particular, the ongoing SBM demonstrates sensitivity to the pitfalls of certain sanitation approaches, while attempting to leverage aspects of other approaches that have proved promising in the past. For example, unlike pure CLTS programmes, SBM places a premium on the construction of high-quality toilets (with the aid of government subsidies) from the outset. However, in the CLTS tradition, SBM combines peer pressure at community level with political support from the highest levels of government and civil society - all the while providing technical training and market development support to local entrepreneurs. The cookstove sector can learn from this 
by applying CLTS principles in the first instance to trigger community-wide reflection and consensus on the health implications of HAP. In practice - especially in the absence of external financial input - this triggering will likely only be sufficient to move communities from traditional stoves to low-tech ICS (the parallel of moving from open defecation to unimproved latrines in sanitation), a suboptimal outcome given that such technologies have been shown to have limited impacts on HAP reduction. Cookstove practitioners could improve on this outcome by drawing further on lessons from sanitation: they could, as the SBM does, complement CLTS principles with external financial, technical and political support to provide communities with the resources they need to "leapfrog" from biomass stoves and fuels to modern cooking energy sources like LPG and biofuels.

There are indeed indications that, for these modern fuels, the inadequacy of technological and market infrastructure is one of the most significant barriers to widespread uptake, especially in rural communities (Kumar et al. 2016). A recent twopart systematic review of factors influencing the uptake of both ICS and clean cookstoves highlights the need to pay attention to demand creation and supply chain management for both kinds of intervention, especially if communities in the so-called "last mile" are to be reached (Puzzolo et al. 2016, Rehfuess et al. 2014). While the key components and actors in these supply chains vary by technology and geography (i.e. rural or urban), uptake and use of clean cookstoves (especially LPG) has been found to be highest in urban areas, where the economic incentive to reduce biomass use is sufficiently high (ibid.).

In poor rural areas where the majority of biomass users live (Kanagawa and Nakata 2007), contextual factors inhibit the uptake of clean cookstoves and fuels to a greater extent, even when demand and supply are present. Further, even in households 
that have adopted clean cookstoves, the widespread practice of stove/fuel stacking, described earlier, often puts the goal of exclusive use out of reach. The practice of stacking is so widespread that Puzzolo et al. (2016) found in their review that the only exceptions to it are mostly urban households on the higher end of the income/expenditure spectrum that can afford to rely solely on clean fuels. The reasons for the persistence of stacking are complex (Rosenbaum et al. 2015, Akintan et al. 2017). Just as it has been shown in the sanitation sector that people do not necessarily practise OD due to the absence of toilets (Bardosh 2015, Coffey et al. 2014, Clasen at al. 2014, O'Reilly et al. 2017, Patil et al. 2014), people also do not retain their traditional stoves necessarily due to a lack of improved alternatives. In rural areas especially, where ICS are expected to remain relevant for some time to come despite their limited value addition (Rehfuess et al. 2014), a responsive approach, like the multi-level approaches that have been operationalised in sanitation, would tap into communities' motivations for stacking while providing them with the institutional and infrastructural frameworks they need to gradually incorporate cleaner stoves and fuels. As Rehfuess et al. (2014) point out, the practice of stacking itself may play an integral role in the journey towards zero emissions, as it presents households with the opportunity to continually reconfigure the range of cooking technologies that they use.

The idea that the cookstove sector has much to learn from sanitation interventions that begin from the standpoint of people's priorities and current practices, rather than from the point of view of the benefits promised by particular technologies, is an underlying theme of this paper. Several sanitation approaches focus on igniting user drive on the basis of aspirations that people themselves value; aspirations that are usually already present and which need to be elicited and embraced in the first instance by external actors seeking to promote change (Jenkins and Curtis 2005). Existing ICS 
research provides glimpses into how this might apply to HAP reduction. For example, the embarrassment that men in western Kenya have historically felt at having sootstained walls in their homes (much like the feelings of disgust at OD triggered by CLTS) (Sesan 2011) could feed into a broader campaign for cleaner houses, which could then help to address the issue of indoor smoke.

The Kenya example above highlights a key point: that learning from the sanitation sector would not require cookstove promoters to start from scratch, as the suite of behaviour change interventions in the field already offers a number of insights that can be built on to motivate change at a deeper level. Bhojvaid et al. (2014), for instance, have shown how the institution of social norms around the acquisition of ICS can be important for legitimising adoption in particular communities. Similarly, Beltramo et al. (2014) showed that the men in a particular study community were willing to pay significantly more than women for the same ICS, indicating that interventions would benefit from targeting entire communities at once rather than narrowly defined groups of users who may not have the framework of social support needed to back their individual choices. The emphasis on targeting social norms here is important because, as Aboud and Singla (2012) highlight, behaviours that are implicitly or explicitly endorsed by community structures often prove difficult to change because they are backed by the authority of tradition. As has been highlighted earlier, these are the kinds of norms and structures with respect to sanitation that have been targeted by contextually grounded yet multi-level approaches such as IBM-WASH and CLTS.

The drawbacks of the contextually grounded approaches described here are that they are both painstaking and time-consuming, with no guarantee that they will deliver appreciable scale-up impacts (UNICEF 2013). However, such approaches facilitate the likelihood of sustaining whatever degree of change is realised. As has been shown in the 
sanitation sector, simultaneously stirring up user motivation - and subsequently demand - and addressing the gaps in market opportunity and financial ability that exist for many target groups is more likely than standalone approaches to deliver the desired outcomes in behaviour change (Jenkins and Curtis 2005). Herein lies the potential pay-off of a responsive approach for mainstream cookstove actors: though it is demand-led, it relies on supply-side innovation to be fully effective (Crocker et al. 2017). Therefore, rather than centre debates around the distinguishing characteristics of particular stoves/fuels or their relative efficiencies, cookstove practitioners ought to learn from the sanitation sector and follow its lead (in recognising that greater balance is required between demand-led and supply-focused approaches for any intervention to succeed from a user standpoint (Coombes 2011, Tsinda et al. 2015).

In the future, research needs to be conducted into what would constitute intrinsic motivators for change in different local contexts, and how these may be used as the starting point for responsive multi-level interventions in the cookstove sector. The enduring challenge would be to keep identifying the contextual and psychosocial characteristics of communities (in the tradition of IBM-WASH) that might make them amenable to such an approach, as well as specific strategies that would be required to match the motivations and opportunities identified at community/societal level with purchasing ability for individual households.

\section{Word count: 6680}

\section{Acknowledgements}

This review was supported by a grant from the UK Engineering and Physical Sciences Research Council, the UK Department for International Development, and the UK Department of Energy and Climate Change under the "Understanding Sustainable Energy Solutions" research 
programme. The authors would like to thank the reviewers and editor for their constructive comments on earlier drafts of the paper.

Declaration of interest statement

The authors report no conflict of interest.

References

Aboud FE, Singla DR. 2012. Challenges to changing health behaviours in developing countries: A critical overview. Soc Sci Med. 75:589-594.

Abraham C, Michie S. 2008. A taxonomy of behavior change techniques used in interventions. Health Psychol. 27(3):379-387.

Agbemabiese L, Nkomo J, Sokona Y. 2012. Enabling innovations in energy access: An African perspective. Energy Policy 47:38-47.

Akintan K, Jewitt S, Clifford M. 2017. Culture, tradition, and taboo: Understanding the social shaping of fuel choices and cooking practices in Nigeria. Energy Res Soc Sci. 40:14-22

Alexander K, Allton C, Felsman C, Hahn M, Okegbe T, Palmer D, Taglieri J, Thibert M. 2016. Ending open defecation in India: insights on implementation and behavior change for Swachh Bharat Abhiyan. Princeton (NJ): Woodrow Wilson School of Public \& International Affairs.

Amegah AK, Quansak R, Jaakkola JJK. 2014. Household air pollution from solid fuel use and risk of adverse pregnancy outcomes: a systematic review and meta-analysis of the empirical evidence. PLoS One 9(12):doi:10.1371/journal.pone.0113920

Bailis R, Cowan A, Berrueta V, Masera O. 2009. Arresting the killer in the kitchen: the promises and pitfalls of commercializing improved cookstoves. World Dev. 37: 16941705. 
Bardosh K. 2015. Achieving "total sanitation” in rural African geographies: poverty, participation and pit latrines in Eastern Zambia. Geoforum 66:53-63.

Barnes BR. 2014. Behavioural change, indoor air pollution and child respiratory health in developing countries: a review. Int J Environ Res Public Health 11:4607-4618.

Barnes B, Rosenbaum J, Mehta S, Williams KN, Jagoe K, Graham J. 2015. Behavior change communication: a key ingredient for advancing clean cooking. J Health Commun. 20:3-5.

Barrington DJ, Sridharan S, Saunders SG, Souter RT, Bartram J, Shields KF, Meo S, Kearton A, Hughes RK. 2016. Improving community health through marketing exchanges: a participatory action research study on water, sanitation, and hygiene in three Melanesian countries. Soc Sci Med. 171:84-93.

Barstow CK, Ngabo F, Rosa G, Majorin F, Boisson S, Clasen T, Thomas EA. 2014. Designing and piloting a program to provide water filters and improved cookstoves in Rwanda. PLoS One 9(3):1-12.

Beltramo T, Blalock G, Levine DI. 2014. The effect of marketing messages, liquidity constraints, and household bargaining on willingness to pay for a nontraditional cookstove. Berkeley (CA): Center for Effective Global Action. Working Paper Series No. WPS-03.

Bhojvaid V, Jeuland M, Kar A, Lewis JJ, Pattanayak SK, Ramanathan N, Ramanathan V, Rehman IH. 2014. How do people in rural India perceive improved stoves and clean fuel? Evidence from Uttar Pradesh and Uttarakhand. Int. J. Environ. Res. Public Health $11: 1341-1358$

Bongartz P, Chambers R. 2009. Beyond subsidies - triggering a revolution in rural sanitation. Brighton: Institute of Development Studies.

Briscoe C, Aboud F. 2012. Behaviour change communication targeting four health behaviours in developing countries: a review of change techniques. Soc. Sci. Med $75: 612-621$. 
Bruce NG, Dherani MK, Das JK, Balakrishnan K, Adair-Rohani H, Bhutta ZA, Pope D. 2013. Control of household air pollution for child survival: estimates for intervention impacts. BMC Public Health 13(Suppl 3):S8.

Bruce N, Pope D, Rehfuess E, Balakrishnan K, Adair-Rohani H, Dora C. 2015. WHO indoor air quality guidelines on household fuel combustion: strategy implications of new evidence on interventions and exposure-risk functions. Atmospheric Environment $106: 451-457$.

Cavill S, Chambers R, Vernon N. 2015. Sustainability and CLTS: taking stock.

Brighton: Institute of Development Studies.

Clark ML, Heiderscheidt JM, Peel JL. 2015. Integrating behavior change theory and measures into health-based cookstove interventions: a proposed epidemiologic research agenda. J Health Commun 20:94-97.

Clifford M. 2014. Viewpoints: Interview with Kirk Smith, Professor of Global Environmental Health, University of California, Berkeley. Boiling Point 64:10-11.

Coffey D, Gupta A, Hathi P, Khurana N, Spears D, Srivastav N, \& Vyas S. 2014. Squat research brief 1: Ending open defecation requires changing minds. RICE Institute. [accessed 2018 Feb 6]:

http://www.communityledtotalsanitation.org/sites/communityledtotalsanitation.org/file s/media/Squat_brief_no1.pdf

Coombes Y. 2011. Partnering on the road towards achieving total sanitation in East Africa. Washington (DC): World Bank Water and Sanitation Program.

Curtis VA, Danquah LO, Aunger RV: Planned, motivated and habitual hygiene behaviour: an eleven country review. Health Educ Res 2009, 24(4):655-673.

Crewe E. 1997. The silent traditions of developing cooks. In: Grillo R, Stirrat R, editors. Discourses of development: anthropological perspectives. Oxford and New York (NY): Berg; p. 59-80. 
Crocker J, Saywell D, Batram, J. 2017. Sustainability of community-led total sanitation outcomes: evidence from Ethiopia and Ghana. International Journal of Hygiene and Environmental Health 220(3):551-557.

Devine J. 2009. Introducing SaniFOAM: a framework to analyze sanitation behaviors to design effective sanitation programs. Washington (DC): World Bank Water and Sanitation Program.

Dickin S, Bisung E, Savadogo, K. 2017. Sanitation and the commons: the role of collective action in sanitation use. Geoforum 86:118-126.

Dreibelbis R, Winch P, Leontsini E, Hulland K, Ram P, Unicomb L and Luby S. 2013. The Integrated Behavioural Model for Water, Sanitation, and Hygiene: a systematic review of behavioural models and a framework for designing and evaluating behaviour change interventions in infrastructure-restricted settings. BMC Public Health 13:1015 http://www.biomedcentral.com/1471-2458/13/1015

Drijver C. 1991. People's participation in environmental projects in developing countries. Landscape and Urban Planning 20:129-139.

Engel S, Susilo A. 2014. Shaming and sanitation in Indonesia: A return to colonial public health practices. Development \& Change 45(1):157-178.

Evans WD, Pattanayak SK, Young S, Buszin J, Rai S, Bihm JW. 2014. Social marketing of water and sanitation products: a systematic review of peer-reviewed literature. Soc. Sci. Med 110:18-25.

Ezzati M, Kammen DM. 2002. The health impacts of exposure to indoor air pollution from solid fuels in developing countries: knowledge, gaps, and data needs. Environ Health Perspect 110(11):1057-1068.

Figueroa ME, Kincaid DL. 2010. Social, cultural and behavioral correlates of household water treatment and storage. Center Publication HCI 2010-1: Health Communication Insights, Baltimore: Johns Hopkins Bloomberg School of Public Health, Center for Communication Programs. 
Foell W, Pachauri S, Spreng D, Zerriffi H. 2011. Household cooking fuels and technologies in developing economies. Energy Policy 39:7487-7496.

Freire P. 1996. Pedagogy of the oppressed. London: Penguin.

Freeman M, Garn J, Sclar G, Boisson S, Medlicott K, Alexander K, Penakalapati G, Anderson D, Mahtani A, Grimes J, Rehfuess E, Clasen T. 2017. The impact of sanitation on infectious disease and nutritional status: a systematic review and metaanalysis. Int J Hyg Environ Health 220:928-949.

[GACC] Global Alliance for Clean Cookstoves. 2014. Results report 2014: on target to reach 100 million households with clean and efficient cookstoves and fuels by 2020 . Washington (DC): Global Alliance for Clean Cookstoves.

[GACC] Global Alliance for Clean Cookstoves. [date unknown]. Clean cookstoves and fuels are critical to the success of the post-2015 sustainable development agenda. Washington (DC): Global Alliance for Clean Cookstoves; [accessed 2017 Dec 6]. http://cleancookstoves.org/binary-data/ATTACHMENT/file/000/000/192-1.pdf.

Goodwin NJ, O’Farrell SE, Jagoe K, Rouse J, Roma E, Biran A, Finkelstein EA. 2015. Use of behaviour change techniques in clean cooking interventions: a review of the evidence and scorecard of effectiveness. J Health Commun 20:43-54.

Gutierrez E. 2007. Delivering pro-poor water and sanitation services: the technical and political challenges in Malawi and Zambia. Geoforum 38(5):886-900.

Hanna R, Duflo E, Greenstone M. 2012. Up in smoke: the influence of household behavior on the long-run impact of improved cooking stoves. Cambridge (MA): Massachusetts Institute of Technology Department of Economics.

Harrell S, Toombs C, Young J. 2013. A guide to optimising behaviour change in fuel efficient stove programs; [accessed 2017 Mar 8]. http://www.tractionproject.org/sites/default/files/A\%20Guide\%20to\%20Optimizing\%2 0Behavior\%20Change\%20in\%20Fuel\%20Efficient\%20Stove\%20Programs_Finalv2.pd f. 
Heierli F, Frias J. 2007. One fly is deadlier than 100 tigers: total sanitation as a business and community action in Bangladesh and elsewhere. Bern: Swiss Agency for Development and Cooperation.

Hiemstra-van der Horst G, Hovorka AJ. 2009. Fuelwood: the "other" renewable energy source for Africa? Biomass Bioenergy 33:1605-1616.

Hyden G. 1980. Beyond ujamaa in Tanzania: underdevelopment and an uncaptured peasantry. London: Heinemann.

[IEA] International Energy Agency and World Bank. 2015. Sustainable energy for all 2015: progress toward sustainable energy. Washington (DC): World Bank.

Jary H, Simpson H, Havens D, Manda G, Pope D, Bruce N, Mortimer K. 2016. Household air pollution and acute lower respiratory infections in adults: a systematic review. PLoS One 11(12):doi:10.1371/journal.pone.0167656

Jenkins MW, Curtis V. 2005. Achieving the "good life": Why some people want latrines in rural Benin. Soc Sci Med 61:2446-2459.

Jenkins MW, Scott B. 2007. Behavioral indicators of household decision-making and demand for sanitation and potential gains from social marketing in Ghana. Soc Sci Med 64:2427-2442.

Jenkins MW, Sugden S. 2006. Rethinking sanitation: lessons and innovation for sustainability and success in the new millennium. New York: Human Development Occasional Papers (1992-2007)

Jewitt S, Mahanta A, Gaur K. 2018. Sanitation sustainability, seasonality and stacking: improved facilities for how long, where and whom? Geogr J. https://doi.org/10.1111/geoj.12258

Johnson MA, Chiang RA. 2015. Quantitative stove use and ventilation guidance for behavior change strategies. J Health Commun 20 Suppl 1:6-9. 
Kanagawa M, Nakata T. 2007. Analysis of the energy access improvement and its socio-economic impacts in rural areas of developing countries. Ecol Econ 62(2):319329.

Kar K. 2003. Subsidy or self-respect? Participatory total community sanitation in Bangladesh. Brighton: Institute of Development Studies. Working Paper No. 184.

Kar K, Pasteur K. 2005. Subsidy or self-respect? Community led total sanitation. An update on recent developments. Brighton: Institute of Development Studies. Working Paper No. 257.

Karekezi S, Murimi N. 1995. The power of the stove: energy, environment and economy. In: Westhoff B, Germann D, editors. Stove images: a documentation of improved and traditional stoves in Africa, Asia and Latin America. Frankfurt: Brandes and Apsel; p. 20-21.

Khennas S. 2003. Stoves for rural livelihoods. Rugby: Intermediate Technology Development Group.

Kumar P, Rao RK, Reddy NH. 2016. Sustained uptake of LPG as cleaner cooking fuel in rural India: role of affordability, accessibility, and awareness. World Dev Perspect $4: 33-37$.

Lewis JJ, Bhojvaid V, Brooks N, Das I, Jeuland MA, Patange O, Pattanayak FK. 2015. Piloting improved cookstoves in India. J Health Commun 20:28-42.

Lim SS, Vos T, Flaxman AD, Danaei G, Shibuya K, Adair-Rohani H, AlMazroa MA, Amann M, Anderson HR, Andrews KG, et al. 2012. A comparative risk assessment of burden of disease and injury attributable to 67 risk factors and risk factor clusters in 21 regions, 1990-2010: A systematic analysis for the global burden of disease study 2010. Lancet 380:2224-2260.

MacInnis DJ, Moorman C, Jaworski BJ. 1991. Enhancing and measuring consumers' motivation, opportunity, and ability to process brand information from ads. J. Mark $55: 32-53$. 
Martin SL, Arney JK, Mueller LM, Kumakech E, Walugembe F, Mugisha E. 2013. Using formative research to design a behavior change strategy to increase the use of improved cookstoves in peri-urban Kampala, Uganda. Int. J. Environ. Res. Public Health 10:6920-6938.

Martin-Simpson S, Parkinson J, Katsou E. 2017. Measuring the benefits of using market based approaches to provide water and sanitation in humanitarian contexts. J. Environ. Manage. [accessed 2018 Mar 22];[7 p.]. 10.1016/j.jenvman.2017.03.009

Masera O, Saatkamp B, Kammen D. 2000. From linear fuel switching to multiple cooking strategies: A critique and alternative to the energy ladder model. World Dev. 28(12):2083-2103.

McMichael C, Robinson P. 2016. Drivers of sustained hygiene behaviour change: A case study from mid-western Nepal. Soc. Sci. Med 163:28-36.

Mortimer K, Ndamala CB, Naunje AW, Malava J, Katundu C, Weston W, Havens D, Pope D, Bruce NG, Nyirenda M, et al. 2017. A cleaner burning biomass-fuelled cookstove intervention to prevent pneumonia in children under 5 years old in rural Malawi (the Cooking and Pneumonia Study): a cluster randomised controlled trial. Lancet 389:167-175.

[MDWS] Ministry of Drinking Water and Sanitation. 2017. Guidelines for Swachh Bharat Mission (Gramin). [accessed 2018 Jun 14] https://mdws.gov.in/sites/default/files/Complete\%20set\%20guidelines_1.pdf

[MDWS] Ministry of Drinking Water and Sanitation. 2018. Swachh Bharat Mission Gramin. [accessed 2018 Jun 14] http://swachhbharatmission.gov.in/sbmcms/index.htm

Mosler HJ. 2012. A systematic approach to behavior change interventions for the water and sanitation sector in developing countries: a conceptual model, a review, and a guideline. Int J Environ Health Res 22(5):431-449.

Murray A, Ray I. 2010. Back-end users: The unrecognized stakeholders in demanddriven sanitation. J Plan Educ Res 30(1):94-102. 
O’Reilly K, Dhanju R, Goel A. 2017. Exploring "the remote" and "the rural": open defecation and latrine use in Uttarakhand, India. World Dev 93:193-205.

O’Reilly K, Louis E. 2014. The toilet tripod: Understanding successful sanitation in rural India. Health Place 29:43-51.

O'Reilly K. 2010. Combining sanitation and women's participation in water supply: an example from Rajasthan. Dev Pract 20(1):45-56.

Okurut K, Charles KJ. 2014. Household demand for sanitation improvements in lowincome informal settlements: A case of East African cities. Habitat Int: 332-338.

Olopade CO, Frank E, Bartlett E, Alexander D, Dutta A, Ibigbami T, Adu D, Olamijulo J, Arinola G, Karrison T, Ojengbede O. 2017. Effect of a clean stove intervention on inflammatory biomarkers in pregnant women in Ibadan, Nigeria: a randomized controlled study. Environ Int 98:181-190.

Parkes M, Panelli R, Weinstein P. 2003. Converging paradigms for environmental health theory and practice. Environ Health Perspect 111:669-674.

Patil SR, Arnold BF, Salvatore AL, Briceno B, Ganguly S, Colford Jr J, Gertler P. 2014. The effect of India's Total Sanitation Campaign on defecation behaviors and child health in rural Madhya Pradesh: a cluster randomized controlled trial. PLoS Medicine 11(8):doi:10.1371/journal.pmed.1001709

Pattanayak SK, Pfaff A. 2009. Behavior, environment, and health in developing countries: evaluation and valuation. Annu Rev Resour Economics 1:183-217.

Piedrahita R, Dickinson KL, Kanyomse E, Coffey E, Alirigia, R, Hagar Y, Rivera I, Oduro A, Dukic V, Wiedinmyer C, et al. 2016. Assessment of cookstove stacking in Northern Ghana using surveys and stove use monitors. Energy Sustainable Dev. 34:6776.

Puzzolo E, Pope D, Stanistreet D, Rehfuess EA, Bruce NG. 2016. Clean fuels for resource-poor settings: a systematic review of barriers and enablers to adoption and sustained use. Environ Res 146:218-234. 
Quansah R, Semple S, Ochieng CA, Juvekar S, Armah FA, Luginaah I, Emina J. 2017. Effectiveness of interventions to reduce household air pollution and/or improve health in homes using solid fuel in low-and-middle income countries: a systematic review and meta-analysis. Environ Int 103:73-90.

Rehfuess EA, Puzzolo E, Stanistreet D, Pope D, Bruce NG. 2014. Enablers and barriers to large-scale uptake of improved solid fuel stoves: a systematic review. Environ Health Perspect 122(2):120-130.

Rosenbaum J, Derby E, Dutta K. 2015. Understanding consumer preference and willingness to pay for improved cookstoves in Bangladesh. J Health Commun 20:2027.

Rosenthal JP, Borrazzo J. 2015. Saving lives by building bridges between user needs and clean cooking technology. J Health Commun 20:1-2.

Rosenthal J, Balakrishnan K, Bruce N, Chambers D, Graham J, Jack D, Kline L, Masera O, Mehta S, Ruiz Mercado I, Neta G, Pattanayak S, Puzzolo E, Petach H, Punturieri A, Rubinstein A, Sage M, Sturke R, Shankar A, Sherr K, Smith K, Yadama G. 2017. Implementation science to accelerate clean cooking for public health. Environ Health Perspect 125(1):A3-A7.

Ruiz-Mercado I, Masera O. 2015. Patterns of stove use in the context of fuel-device stacking: rationale and implications. Ecohealth 12(1):42-56.

Sanan D, Moulik SG. 2007. Community-led total sanitation in rural areas: an approach that works. Washington (DC): World Bank.

[SEI] Stockholm Environment Institute. 2016. What boosts cookstove uptake? A review of behaviour change approaches and techniques. Sweden: Stockholm Environment Institute.

Sesan T. 2011. What's cooking? Participatory and market approaches to stove development in Nigeria and Kenya [dissertation]. Nottingham: University of Nottingham. 
Sesan T. 2012. Navigating the limitations of energy poverty: Lessons from the promotion of improved cooking technologies in Kenya. Energy Policy 47:202-210.

Shell Foundation. 2013. Social marketing in India: lessons learned from efforts to foster demand for cleaner cookstoves. London: Shell Foundation; [accessed 2017 Dec 6]. http://www.shellfoundation.org/download/pdfs/FINAL+Social+Marketing+in+India.pdf

The Economic Times (2017). 2.5 years on. Swachh Bharat Mission's claims remain unverified. [accessed 2018 February 14].

http://economictimes.indiatimes.com/news/politics-and-nation/2-5-years-on-swachhbharat-missions-claims-remain-unverified/article show/58821020.cms

Thurber MC, Phadke H, Nagavarapu S, Shrimali G, Zerriffi H. 2014. "Oorja” in India: Assessing a large-scale commercial distribution of advanced biomass stoves to households. Energy Sustainable Dev 19:138-150.

Tielsch JM, Katz J, Khatry SK, Shrestha L, Breysse P, Zeger S, Checkley W, Mullany LC, Kozuki N, LeClerq SC, Adhikari R. 2016. Effect of an improved biomass stove on acute lower respiratory infections in young children in rural Nepal: a clusterrandomised, step-wedge trial. Lancet Glob Health 4(S19):doi:10.1016/S2214109X(16)30024-9

Troncoso K, Castillo A, Masera O, Merino L. 2007. Social perceptions about a technological innovation for fuelwood cooking: Case study in rural Mexico. Energy Policy 35:2799-2810.

Tsinda A, Abbott P, Chenoweth J. 2015. Sanitation markets in urban informal settlements of East Africa. Habitat Int 49:21-29.

[UNICEF] United Nations Children's Fund. 2013. Community-led total sanitation in East Asia and Pacific: Progress, lessons and directions. New York (NY): United Nations Children's Fund; [accessed 2017 Dec 6]. https://www.unicef.org/eapro/Community_Led_Total_Sanitation.pdf.

United Nations. 2016. Sustainable Development Goals: 17 goals to transform our world. New York (NY): United Nations; [accessed 2017 Dec 5]. http://www.un.org/sustainabledevelopment/water-and-sanitation/ 
[URC] University Research Co. 2015. Behavior change approaches for clean cooking: background and introduction. Bethesda (MD): University Research Co.

[USAID] United States Agency for International Development. 2014. Open forum on behavior change approaches in the clean cooking sector: summary of key research questions. Washington (DC): United States Agency for International Development; [accessed 2017 Mar 21].

http://www.tractionproject.org/sites/default/files/Notes\%20HAP\%20Open\%20Forum\% 20Discussion\%20March\%2012_Final_0.pdf.

[USAID] United States Agency for International Development, [URC] University Research Co (2015). Behaviour change for clean cooking panel discussion: current knowledge and next steps. Washington (DC): USAID Translating Research into Action (TRAction) Project; [accessed 2018 Jan 10]. https://cleancookstoves.org/binarydata/ATTACHMENT/file/000/000/237-1.pdf.

Venkataraman C, Sagar AD, Habib G, Lam N, Smith KR. 2010. The Indian national initiative for advanced biomass cookstoves: the benefits of clean combustion. Energy Sustainable Dev. 14:63-72.

Waterkeyn J, Cairncross S. 2005. Creating demand for sanitation and hygiene through community health clubs: A cost-effective intervention in two districts in Zimbabwe. Soc. Sci. Med 61:1958-1970.

Wells C, Sijbesma C. 2012. Practical innovations for strengthening community-led total sanitation: Selected experience from Asia. Dev. Pract. 22(3):417-426.

[WHO/UNICEF] World Health Organization / United Nations Children's Fund. 2015. 25 years progress on sanitation and drinking water: update and MDG assessment; [accessed 2010 Sep 10]. http://www.wssinfo.org/fileadmin/user_upload/resources/JMPUpdate-report-2015_English.pdf.

[WHO/UNICEF] World Health Organization / United Nations Children's Fund. 2016. Improved and unimproved water sources and sanitation facilities; [accessed $2016 \mathrm{Feb}$ 22]. http://www.wssinfo.org/definitions-methods/watsan-categories/ 
[WHO/UNICEF] World Health Organization / United Nations Children's Fund 2017.

Progress on drinking water, sanitation and hygiene. [accessed 2018 Feb 14].

https://washdata.org/reports

Wood S, Foster J, Kols A. 2012. Understanding why women adopt and sustain home water treatment: insights from the Malawi antenatal care program. Soc Sci Med 75:634642.

World Bank. 2016. Bangladesh: improving water supply and sanitation. Washington (DC): World Bank; [accessed 2017 May 15].

http://www.worldbank.org/en/results/2016/10/07/bangladesh-improving-water-supplyand-sanitation. 